\title{
ESTABILIDADE FÍSICO-QUÍMICA DE IOGURTES CAPRINOS ADOÇADOS COM MÉIS DE DIFERENTES FLORADAS
}

M. B. DE C. LIMA ${ }^{1}$, E. N. A. DE OLIVEIRA ${ }^{2}$, B. F. FEITOSA ${ }^{3}$, R. M. FEITOSA ${ }^{4}$, P. V. C. DE FREITAS ${ }^{5}$

Instituto Federal de Educação, Ciência e Tecnologia do Rio Grande do Norte ${ }^{1,2}$, Universidade Federal de Campina Grande $^{3,5}$, Instituto Federal de Alagoas ${ }^{4}$

ORCID ID: http://orcid.org/0000-0002-4183-3960

brunofonsecafeitosa@live.com ${ }^{3}$

Submetido 24/01/2020 - Aceito 30/07/2020

DOI: $10.15628 /$ holos. 2020.9453

\section{RESUMO}

A valorização de alimentos regionais, como o mel e leite caprino, pode acelerar o desenvolvimento social e crescimento econômico de regiões produtoras no Brasil. Objetivou-se com esta pesquisa elaborar e avaliar a estabilidade físico-química durante o armazenamento de iogurtes de leite caprino adoçados com méis de diferentes floradas. Os iogurtes de leite de cabra com inulina (5\%) como agente prebiótico foram elaborados, sem adição de mel (padrão) e com adição de mel das floradas silvestre (sem florada predominante), marmeleiro (Croton sonderianus) e juazeiro (Zizyphus joazeiro Mart). Os iogurtes foram avaliados em 5 tempos, durante 40 dias de armazenamento $\left(4{ }^{\circ} \mathrm{C}\right)$ quanto aos parâmetros de extrato seco, cinzas, $\mathrm{pH}$ e acidez total. Os
\end{abstract}

méis atenderam a todos os parâmetros preconizados pela legislação. A adição de mel nos iogurtes caprinos promoveu o aumento dos valores de extrato seco total e redução dos valores de cinzas, $\mathrm{pH}$ e acidez. Durante o armazenamento ocorreu redução dos valores de extrato seco total, cinzas e pH e elevação dos valores de acidez. Os iogurtes apresentaram comportamento físico-químico semelhante durante o armazenamento, destacando-se aqueles adicionados com mel de juazeiro e marmeleiro. Infere-se que os produtos sofreram alterações significativas, sendo necessárias análises complementares para atestar a viabilidade mercadológica.

PALAVRAS-CHAVE: Apis mellifera L., estocagem, leite fermentado, prebióticos

\section{PHYSICAL-CHEMICAL STABILITY OF GOAT YOGURTS SWEETENED WITH HONEYS OF DIFFERENT FLOWERS}

\begin{abstract}
The appreciation of regional foods, such as honey and goat milk, can accelerate the social development and economic growth of producing regions in Brazil. The objective of this research was to elaborate and evaluate the physical-chemical stability during the storage of goat milk yoghurt sweetened with honeys of different flowers. Goat milk yoghurt with inulin (5\%) as a prebiotic agent was prepared without honey (standard) and with honey from sylvan (without predominant flowering), marmeleiro marmeleiro (Croton sonderianus) and juazeiro (Zizyphus joazeiro Mart). The yogurts were evaluated at 5 times, during 40 days of storage $\left(4^{\circ} \mathrm{C}\right)$ for
\end{abstract}

the parameters of dry extract, ash, $\mathrm{pH}$ and total acidity. The honey met all the parameters recommended by the legislation. The addition of honey to goat yogurt promoted the increase of total dry extract values and reduction of ash, $\mathrm{pH}$ and acidity values. During storage, the total dry extract, ash and $\mathrm{pH}$ values decreased and the acidity values increased. Yogurts showed similar physical-chemical behavior during storage, especially those added with juazeiro and marmeleiro honey. It is inferred that the products have undergone significant changes and further analysis is required to attest to market viability.

KEYWORDS: Apis mellifera L., stocking, fermented milk, prebiotics.

HOLOS, Ano 36, v.5, e9453, 2020 


\section{INTRODUÇÃO}

No Semiárido nordestino está localizado cerca de $75 \%$ da produção de leite caprino, destacando-se os estados do Rio Grande do Norte e da Paraíba (JACOPINI et al., 2011). Esta matériaprima nativa contribui para a redução da fome e miséria na região, através do impacto social e econômico exercido pelas possibilidades de obtenção de renda e suprimento das necessidades nutricionais da população. De acordo com Santos et al. (2011), o leite caprino apresenta elevados teores de sais minerais (cálcio, fósforo e potássio) e vitaminas, além de lactose, gorduras e proteínas.

Entretanto, embora o leite caprino ofereça excelentes propriedades funcionais, nutricionais e terapêuticas, os consumidores ainda demonstram rejeição quando oferecido em estado natural, devido ao sabor e aroma característicos (ALVES et al., 2009), sendo necessárias alternativas tecnológicas viáveis para amenizar esta percepção indesejável.

Dentre as principais aplicações industriais para o leite de cabra está o desenvolvimento de derivados fermentados, como o iogurte. De acordo com Braga et al. (2012) e Quintino (2012), os micro-organismos (Lactobacillus bulgaricus e Streptococcus thermophilus) da cultura láctea utilizada na fermentação láctica metabolizam a glicose sob condições específicas de temperatura para a produção de ATP (energia), gerando compostos primários como o ácido lático e o dióxido de carbono.

O iogurte detém um reconhecimento significativo no comércio brasileiro, em virtude da crescente produção, cuja riqueza nutricional constituinte é responsável, possibilitando uma ampla diversificação de variedades, através do enriquecimento com adição de frutas, xaropes, méis, geleias, entre outros alimentos (ALVES et al., 2009).

O mel é um adoçante natural, que além de conferir doçura ao iogurte, proporciona sabor e cor, dependendo de sua origem floral. Segundo a legislação brasileira (Feitosa et al., 2020), o mel é definido como o produto alimentício produzido pelas abelhas melíferas, a partir do néctar das flores ou das secreções procedentes de partes vivas das plantas ou de excreções de insetos sugadores, que as abelhas recolhem, transformam, combinam com substâncias específicas próprias, armazenam e deixam madurar nos favos da colmeia (BRASIL, 2000).

Esse produto apícola pode ser uma opção viável para substituição dos açúcares convencionais, como o açúcar refinado (sacarose), que são utilizados para adoçar produtos lácteos. Conforme Guerra e Mujica (2010) e Jaffe (2015), esses açúcares comumente utilizados possuem um menor número de nutrientes em comparação à outros adoçantes naturais.

Naturalmente, a composição do mel possui açúcares, proteínas, sais minerais e vitaminas (ABADIO FINCO et al., 2010; SANTOS et al., 2014). Tem sido reconhecido nos últimos anos por ser fonte de antioxidantes naturais e por suas propriedades terapêuticas, contribuindo para a saúde do organismo com atividades fitoterápicas, anti-inflamatórias e antimicrobianas (ESCOBAR; XAVIER, 2013; YUCEL; SULTANOGLU, 2013). 
Assim, objetivou-se com esta pesquisa elaborar iogurtes de leite caprino adoçados com méis de diferentes floradas e avaliar sua estabilidade físico-química durante 40 dias de armazenamento.

\section{METODOLOGIA}

Os ingredientes utilizados para a elaboração dos iogurtes foram o leite de cabra esterilizado (Caprilat ${ }^{\circledR}$ ), inulina (INUFLORA 99\%), cultura láctea liofilizada (SACCO - Lyosfast ${ }^{\circledR}$ ) e mel das floradas silvestre, de marmeleiro e juazeiro, obtidos no comércio varejista de Pau dos Ferros-RN. A pesquisa foi realizada no Laboratório de Análise de Alimentos, do Instituto Federal de Educação, Ciência e Tecnologia do Rio Grande do Norte (IFRN), campus Pau dos Ferros -RN.

Os méis de diferentes floradas foram analisados, em triplicata, quanto aos parâmetros físicoquímicos de umidade, sólidos solúveis totais, sólidos insolúveis, acidez total, cor na Escala de Pfund (mm), atividade diastásica, segundo Brasil (1981), pH, cinzas, segundo o IAL (2008), e pesquisa de corantes realizada como descrito pela SBF (2009).

Através de testes preliminares, definiu-se 4 formulações diferenciadas pela ausência ou presença dos tipos de méis com os quais os iogurtes foram adoçados, sendo $I_{p}$ (iogurte padrão sem mel), $I_{1}$ (iogurte com mel silvestre), $I_{2}$ (iogurte com mel de marmeleiro), $I_{3}$ (iogurte com mel de juazeiro).

A reativação da cultura láctea liofilizada foi realizada em condições esterilizadas, diluindo em leite esterilizado uma mistura com proporção de 0,01\%, a qual foi armazenada fracionada sob congelamento $\left(-18^{\circ} \mathrm{C}\right)$.

O processamento dos iogurtes, adaptado de Alves et al. (2009), iniciou adicionando $5 \%$ de inulina no leite de cabra e homogeneizando a mistura, seguida de aquecimento até $45 \pm 2{ }^{\circ} \mathrm{C}$ com agitação constante. Ao atingir a temperatura desejada, inoculou-se a solução reativada da cultura láctea liofilizada na proporção $3 \mathrm{~mL} / \mathrm{L}$, decorrendo a fermentação durante $8 \mathrm{~h}$., em incubadora de Demanda Bioquímica de Oxigênio (BOD) a temperatura de $45 \pm 2{ }^{\circ} \mathrm{C}$.

Após a fermentação, a massa foi refrigerada $\left(4^{\circ} \mathrm{C} / 12 \mathrm{~h}\right.$.) para posterior quebra da coalhada e mistura com agitação, para obtenção das 4 bateladas, sendo uma para cada tipo de iogurte, obtendo-se o iogurte padrão (sem adição de mel) e os produtos adoçados com mel de abelha foram adicionados de $10 \%$ de mel nas respectivas formulações para cada tipo de mel (florada), sendo todos acondicionados em recipientes de polietileno $(100 \mathrm{~mL})$ e armazenados a $4 \pm 2{ }^{\circ} \mathrm{C}$, durante 40 dias. Durante o armazenamento foi avaliada a estabilidade físico-química dos iogurtes a cada 10 dias, em triplicata, quanto aos parâmetros de extrato seco, cinzas, pH e acidez total (IAL, 2008).

Para a análise estatística, utilizou-se o programa computacional Assistat versão 7.7 beta (SILVA; AZEVEDO, 2016), através de Análise de Variância (ANOVA), com Delineamento Inteiramente Casualizado em esquema fatorial $4 \times 5$ ( 4 tipos de iogurtes e 5 tempos de armazenamento). A comparação de médias foi realizada pelo Teste de Tukey em nível de $5 \%$ de significância $(p<0,05)$. 


\section{RESULTADOS E DISCUSSÕES}

Os valores encontrados na caracterização dos méis de diferentes floradas estão apresentados na Tabela 1. A Instrução Normativa $\mathrm{n} 011$, de 20 de outubro de 2000, regulamenta os padrões de identidade e qualidade do mel (BRASIL, 2000). As determinações realizadas são importantes por permitirem o conhecimento da composição físico-química individual das diferentes matérias-primas utilizadas para a elaboração dos iogurtes caprinos. Também propicia compreender sua qualidade, atendimento aos padrões de identidade e qualidade preconizados pela legislação e possível influência nos parâmetros do produto elaborado.

Tabela 1: Qualidade físico-química dos méis utilizados para elaboração dos iogurtes caprinos.

\begin{tabular}{|c|c|c|c|c|}
\hline \multirow{2}{*}{ Parâmetros } & \multirow{2}{*}{ Legislação* } & \multicolumn{3}{|c|}{ Méis de diferentes floradas } \\
\hline & & Silvestre & Marmeleiro & Juazeiro \\
\hline Umidade (\%) & Máx. 20,00 & $20,00 \pm 0,00$ & $19,50 \pm 0,00$ & $20,00 \pm 0,00$ \\
\hline Cinzas (\%) & Máx. 0,60 & $0,02 \pm 0,02$ & $0,02 \pm 0,02$ & $0,07 \pm 0,01$ \\
\hline Sólidos solúveis totais ( ${ }^{\circ} \mathrm{Brix}$ ) & - & $77,00 \pm 0,00$ & $76,50 \pm 0,00$ & $78,50 \pm 0,00$ \\
\hline Sólidos insolúveis (\%) & Máx. 0,10 & $0,04 \pm 0,08$ & $0,05 \pm 0,21$ & $0,05 \pm 0,15$ \\
\hline $\mathrm{pH}$ & - & $3,84 \pm 0,07$ & $3,76 \pm 0,01$ & $4,14 \pm 0,04$ \\
\hline Acidez total (mEq/Kg) & Máx. 50,00 & $39,83 \pm 1,89$ & $41,65 \pm 2,02$ & $43,33 \pm 1,04$ \\
\hline Cor & Incolor a parda escura & Branco & Âmbar claro & Âmbar escuro \\
\hline Pesquisa de corantes & Ausente & Ausente & Ausente & Ausente \\
\hline Atividade diastásica & Presente & Presente & Presente & Presente \\
\hline
\end{tabular}

*Instrução Normativa no 11, de 20 de outubro de 2000 (BRASIL, 2000).

Observa-se que os méis de diferentes floradas apresentaram-se dentro dos padrões estabelecidos pela legislação (BRASIL, 2000) para umidade e resíduo mineral (cinzas). Evidencia-se, portanto, méis com elevadas concentrações de água, com limites bem próximos do máximo estabelecido pela legislação, o que pode representar que os méis foram colhidos no limite do início de sua maturidade. Resultados semelhantes para umidade de 40 amostras de méis coletados em Terra Roxa $(19,22 \%)$ e Santa Helena-PA (19,53\%) foram reportados por Moraes et al. (2014).

Quanto aos teores de sólidos solúveis totais, o mel de juazeiro demonstrou uma maior concentração de sólidos solúveis totais, com 78,50 @Brix, estando semelhante a média de 78,48 @Brix obtida por Oliveira e Santos (2011), que avaliaram 16 amostras de méis no Nordeste brasileiro. 
Nenhum dos méis analisados ultrapassou o máximo de $0,1 \%$ de sólidos insolúveis estabelecido pela legislação brasileira (BRASIL, 2000).

As variações no $\mathrm{pH}$ dos méis refletem fatores como o pH do néctar, solo ou associação dos vegetais e substâncias mandibulares das abelhas (PÉRICO et al., 2011). O mel de marmeleiro apresentou-se com menor $\mathrm{pH}$, de forma semelhante aos valores médios de 3,97 (oito méis de abelha nativa) e 3,50 (oito méis de abelha africanizada) encontrados por Oliveira e Santos (2011), coletados Mauriti e Limoeiro do Norte-CE, respectivamente.

Quanto a acidez, todas as amostras avaliadas apresentaram-se dentro dos limites especificados pela legislação (BRASIL, 2000). Os ácidos orgânicos presentes no néctar durante sua transformação influenciam os resultados de acidez do mel e, consequentemente, a estabilidade deste produto, visto que nele é originado o ácido glucônico pela ação da enzima glicose-oxidase (OLIVEIRA; SANTOS, 2011).

As cores presentes nas amostras analisadas variaram do âmbar claro ao âmbar escuro, conforme a Escala de Pfund $(\mathrm{mm})$, apresentando-se como branco somente o mel silvestre. Segundo Lacerda et al. (2010), diversos fatores podem alterar a cor do mel, como a origem floral, condições de armazenamento e possíveis reações enzimáticas ou aquecimento.

Os méis desta pesquisa apresentaram ausência de corantes e presença de atividade diastásica. A legislação brasileira não permite a adição de corantes de qualquer natureza, assim como de outros componentes (edulcorantes, essências aromatizantes, amido, gelatinas ou redutores de acidez) (BRASIL, 2000). A enzima diastásica é uma indicadora do grau de conservação e possível aplicação de aquecimento excessivo, provocando a desnaturação desta enzima. A presença da enzima reforça que os méis não possuem indícios de adulteração por possível aquecimento com adição de xarope de sacarose.

Com a caracterização dos méis de diferentes floradas, observou-se que as matérias-primas estão dentro dos padrões exigidos pela legislação vigente, na Instrução Normativa no 11, de 20 de outubro de 2000. Logo, torna-se possível o emprego para a elaboração do iogurte caprinos.

Na Tabela 2 estão expressos os resultados da estabilidade físico-química durante 40 dias de armazenamento dos iogurtes caprinos adoçados com méis de diferentes floradas. A Instrução Normativa n. 46, de 23 de outubro de 2007, regulamenta os padrões de identidade e qualidade de leites fermentados (BRASIL, 2007). 
Tabela 2: Estabilidade físico-química durante o armazenamento dos iogurtes caprinos adoçados com méis de diferentes floradas.

\begin{tabular}{|c|c|c|c|c|c|c|}
\hline \multirow{2}{*}{ Parâmetros } & \multirow{2}{*}{ logurtes } & \multicolumn{5}{|c|}{ Armazenamento (dias) } \\
\hline & & 0 & 10 & 20 & 30 & 40 \\
\hline \multirow{4}{*}{$\begin{array}{l}\text { Extrato } \\
\text { seco (\%) }\end{array}$} & $I_{p}$ & $10,51^{\mathrm{bA}} \pm 0,89$ & $9,48^{\mathrm{cA}} \pm 0,43$ & $10,30^{\mathrm{cA}} \pm 0,23$ & $9,49^{\mathrm{cA}} \pm 0,06$ & $10,26^{\mathrm{CA}} \pm 0,17$ \\
\hline & $\mathrm{I}_{1}$ & $15,87^{\mathrm{aA}} \pm 0,78$ & $15,13^{\mathrm{bAB}} \pm 0,09$ & $14,41^{\mathrm{bB}} \pm 0,28$ & $15,14^{\mathrm{bAB}} \pm 0,11$ & $14,85^{\mathrm{bAB}} \pm 0,19$ \\
\hline & $\mathrm{I}_{2}$ & $16,15^{\mathrm{aA}} \pm 0,11$ & $15,59^{\mathrm{bA}} \pm 0,14$ & $15,74^{\mathrm{aA}} \pm 0,88$ & $15,36^{\mathrm{bA}} \pm 0,21$ & $15,41^{\mathrm{bA}} \pm 0,57$ \\
\hline & $\mathrm{I}_{3}$ & $17,39^{\mathrm{aA}} \pm 0,10$ & $17,46^{\mathrm{aA}} \pm 0,11$ & $16,85^{\mathrm{aA}} \pm 0,61$ & $16,75^{\mathrm{aA}} \pm 0,51$ & $17,24^{\mathrm{aA}} \pm 0,23$ \\
\hline \multirow{4}{*}{$\begin{array}{c}\text { Cinzas } \\
(\%)\end{array}$} & $I_{p}$ & $0,81^{\mathrm{aA}} \pm 0,01$ & $0,72^{\mathrm{aB}} \pm 0,01$ & $0,63^{a c} \pm 0,02$ & $0,70^{\mathrm{aB}} \pm 0,03$ & $0,69^{\mathrm{aBC}} \pm 0,04$ \\
\hline & $\mathrm{l}_{1}$ & $0,65^{\mathrm{cAb}} \pm 0,04$ & $0,61^{\mathrm{bcAB}} \pm 0,02$ & $0,56^{\mathrm{bBC}} \pm 0,05$ & $0,50^{c C} \pm 0,01$ & $0,55^{\mathrm{bBC}} \pm 0,06$ \\
\hline & $\mathrm{I}_{2}$ & $0,71^{\mathrm{bA}} \pm 0,02$ & $0,66^{\mathrm{abAB}} \pm 0,02$ & $0,58^{\mathrm{abCD}} \pm 0,01$ & $0,57^{c D} \pm 0,06$ & $0,64^{\mathrm{aBC}} \pm 0,01$ \\
\hline & $\mathrm{I}_{3}$ & $0,71^{\mathrm{bcA}} \pm 0,01$ & $0,59^{\mathrm{cB}} \pm 0,01$ & $0,53^{\mathrm{bB}} \pm 0,02$ & $0,57^{\mathrm{bB}} \pm 0,01$ & $0,54^{\mathrm{bB}} \pm 0,05$ \\
\hline \multirow{5}{*}{$\mathrm{pH}$} & $I_{p}$ & $4,66^{\mathrm{aA}} \pm 0,03$ & $4,58^{\mathrm{aB}} \pm 0,02$ & $4,46^{\mathrm{ac}} \pm 0,04$ & $4,58^{\mathrm{aB}} \pm 0,03$ & $3,95^{\mathrm{aD}} \pm 0,03$ \\
\hline & $\mathrm{l}_{1}$ & $4,60^{\mathrm{aA}} \pm 0,01$ & $4,50^{\mathrm{aB}} \pm 0,03$ & $4,53^{\mathrm{aB}} \pm 0,08$ & $4,47^{\mathrm{aB}} \pm 0,01$ & $3,81^{b c} \pm 0,02$ \\
\hline & la & $59^{a A}+001$ & בח & $59^{a A}+004$ & $50^{a A B}+0 \Omega 3$ & $377^{c c}+0$ \\
\hline & 12 & $4,59 \pm 0,01$ & $4,4 b^{2} \pm 0,02$ & $4,59 \pm 0,04$ & $4,5 U^{2} \pm 0,03$ & $3,17 \pm 0,02$ \\
\hline & $\mathrm{I}_{3}$ & $4,62^{\mathrm{aA}} \pm 0,00$ & $4,50^{\mathrm{aB}} \pm 0,01$ & $4,58^{\mathrm{aA}} \pm 0,01$ & $4,51^{\mathrm{aB}} \pm 0,05$ & $3,81^{\mathrm{bc}} \pm 0,02$ \\
\hline \multirow{4}{*}{$\begin{array}{l}\text { Acidez total (\% } \\
\text { ácido lático) }\end{array}$} & $I_{p}$ & $0,83^{\mathrm{ac}} \pm 0,03$ & $0,85^{\mathrm{bBC}} \pm 0,01$ & $0,88^{\mathrm{aB}} \pm 0,01$ & $0,95^{\mathrm{aA}} \pm 0,01$ & $0,98^{\mathrm{aA}} \pm 0,01$ \\
\hline & $\mathrm{l}_{1}$ & $0,75^{\mathrm{aD}} \pm 0,02$ & $0,79^{\mathrm{CCD}} \pm 0,03$ & $0,81^{\mathrm{bBC}} \pm 0,02$ & $0,85^{\mathrm{bAB}} \pm 0,01$ & $0,87^{\mathrm{bA}} \pm 0,01$ \\
\hline & $\mathrm{I}_{2}$ & $0,80^{\mathrm{ac}} \pm 0,05$ & $0,89^{\mathrm{aB}} \pm 0,03$ & $0,91^{\mathrm{aB}} \pm 0,01$ & $0,92^{\mathrm{aB}} \pm 0,02$ & $0,97^{\mathrm{aA}} \pm 0,02$ \\
\hline & $\mathrm{I}_{3}$ & $0,78^{\mathrm{ac}} \pm 0,03$ & $0,83^{\mathrm{bcB}} \pm 0,01$ & $0,84^{\mathrm{bAB}} \pm 0,02$ & $0,85^{\mathrm{bAB}} \pm 0,02$ & $0,88^{\mathrm{bA}} \pm 0,01$ \\
\hline
\end{tabular}

$I_{p}$ - logurte padrão; $I_{1}$ - logurte com mel silvestre; $I_{2}$ - logurte com mel de marmeleiro; $I_{3}$ - logurte com mel de juazeiro;. Médias seguidas na coluna pela mesma letra minúscula e na linha pela mesma letra maiúscula não diferem estatisticamente entre si pelo teste de Tukey a 5\% de significância.

Observa-se no tempo inicial (0 dias) que a adição de mel provocou o aumento do teor de extrato seco em cerca de $5 \%$ para todos os iogurtes caprinos, o que era esperado devido a composição rica em sólidos solúveis totais, principalmente açúcares. Os produtos elaborados com mel diferiram significativamente do iogurte $I_{p}$ elaborado sem mel, mas não diferiram entre si $(p<0,05)$. $O$ iogurte $I_{3}$ indicou o maior teor numérico de extrato seco, possivelmente devido ao maior teor de sólidos solúveis totais na avaliação físico-química do mel de juazeiro (78,50 Brix) observado na Tabela 1. Durante o armazenamento, os iogurtes demonstraram boa estabilidade para o teor de 
extrato seco nessas condições experimentais. A inulina adicionada nos iogurtes pode ter contribuído com a estabilidade, devido a capacidade umectante (PIMENTEL et al., 2012a), dando mais corpo/consistência aos iogurtes.

A adição de mel nos iogurtes influenciou significativamente $(p<0,05)$ nos valores de resíduo mineral (cinzas). No tempo inicial (0 dias), os iogurtes com adição de mel apresentaram menor teor de cinzas em relação ao iogurte padrão, o que pode ser justificado pela diluição na constituição dos produtos em decorrência da adição do mel, cuja composição apresenta reduzida concentração de cinzas. As concentrações de cinzas podem ser alteradas como consequência das diferentes matérias-primas ou substâncias adicionadas para conferir cor e sabor, bem como devido suas concentrações empregadas nas formulações de leites fermentados. Ao decorrer do armazenamento ocorreram oscilações neste parâmetro em todos os iogurtes, apresentando diferenças significativas $(p<0,05)$. $O$ iogurte $I_{1}$ indicou o menor teor numérico de extrato seco, variando de $0,65 \%$ ( 0 dias de armazenamento) a 0,55\%, após 40 dias de armazenamento. É possível que a composição de cinzas nos iogurtes corresponda principalmente a presença de cálcio, magnésio, fósforo e potássio, sendo os resultados obtidos semelhantes ao percentual de $0,74 \%$ de resíduo mineral em iogurte light com adição de 3\% de inulina e adoçado com mel, elaborado por Silva et al. (2017).

Quanto aos valores de $\mathrm{pH}$, no tempo inicial (0 dias) não houve diferença significativa $(p<0,05)$ entre os iogurtes. Nos tempos 10, 20 e 30 dias de armazenamento também não ocorreram diferença significativa $(p<0,05)$ entre os iogurtes. Todos os iogurtes apresentaram uma diminuição do $\mathrm{pH}$ significativa $(p<0,05)$ durante o armazenamento. Esse fato pode estar relacionado a produção de ácidos decorrente da multiplicação de micro-organismos, como as bactérias ácido-láticas, que atuam em pH ótimo, produzindo ácido lático e dióxido de carbono ao consumir a lactose como nutriente (FARIAS et al., 2016). Pimentel et al. (2012b) obtiveram uma redução média de 4,45 a 4,23 para o $\mathrm{pH}$ de iogurte probiótico com frutano tipo inulina de médio grau de polimerização. Enquanto isso, Mazloomi et al. (2011) observaram a variação de 6,51 a 4,29 para o pH de iogurte adicionado de $2 \%$ de inulina com baixo teor de gordura.

Como esperado, a acidez total apresentou-se elevada no tempo inicial, com uma variação de 0,75 a $0,83 \%$ em ácido lático. Os iogurtes não apresentaram diferença significativa $(p<0,05)$. os produtos permaneceram ao decorrer do armazenamentos conforme a variação entre 0,6 e 1,5\% preconizado para a acidez total de acordo com a legislação vigente (BRASIL, 2007). Durante o armazenamento, esse parâmetro apresentou comportamento inversamente proporcional ao $\mathrm{pH}$. Os iogurtes apresentaram diferença significativa $(p<0,05)$ ao decorrer da estocagem. $O$ iogurte $I_{2}$, adicionado de mel de marmeleiro, indicou numericamente a maior concentração de acidez total, variando de $0,80 \%$ ( 0 dias de armazenamento) a 0,97\%, após 40 dias de armazenamento. Isso pode ser considerado positivo, devido a possível inibição das bactérias deteriorantes, que não conseguem se desenvolver nesta faixa de acidez. Semelhante a esta pesquisa, Mazloomi et al. (2011) também obtiveram aumento da acidez total (0,16-0,73\%) ao avaliar iogurte com baixo teor de gordura, durante 14 dias de armazenamento. 


\section{CONCLUSÃO}

Os méis atenderam aos padrões de identidade e qualidade preconizados pela legislação, apresentando qualidade físico-química adequada para a elaboração dos iogurtes. Os iogurtes de leite caprino adoçados com méis de diferentes floradas apresentaram comportamento físicoquímico semelhante ao iogurte padrão durante o período armazenamento.

Observou-se boa estabilidade físico-química no parâmetro extrato seco para todos os produtos, apesar de que sofreram alterações significativas nos demais parâmetros. Recomenda-se o consumo até os 30 dias de armazenamento, no tocante aos parâmetros de pH e acidez total titulável.

\section{REFERÊNCIAS}

ABADIO FINCO, F.D.B., MOURA, L.L., SILVA, I.G. (2010). Propriedades físicas e químicas do mel de Apis mellifera L. Ciênc Tecnol Aliment [periódico na internet]; 30(3):706-712.

ALVES, L.L, RICHARDS, N.S.P.S., BECKER, L.V., ANDRADE, D.F., MILANI, L.I.G., REZER, A.P.S,, SCIPIONI, G.C. (2009). Aceitação sensorial e caracterização de frozen yogurt de leite de cabra com adição de cultura probiótica e prebiótico. Cienc. Rural [periódico na internet], 39(9):2595-2600.

BRAGA, A.C.C., Neto, E.F.A., Vilhena, M.J.V. (2012). Elaboração e caracterização de iogurtes adicionados de polpa e de xarope de Mangostão. Rev Bras Prod Agroindustriais [periódico na internet];14(1):77-84.

BRASIL. Ministério da Agricultura, Pecuária e Abastecimento. (2000, Out 11.). Instrução Normativa n. 11, de 20 de outubro de 2000. Regulamento técnico de identidade e qualidade do mel. Diário oficial [da] República Federativa do Brasil.

BRASIL. Ministério da Agricultura. (2007, out. 24) Pecuária e Abastecimento. Instrução Normativa n. 46, de 23 de outubro de 2007. Regulamento técnico de identidade e qualidade de leites fermentados. Diário Oficial da União, 2007, Seção 1, pág. 4.

BRASIL. Ministério da Agricultura. (1981, out. 13). Secretaria Nacional de Defesa Agropecuária. Laboratório Nacional de Referência Animal (LANARA). Portaria no 01, de 07 de outubro de 1981. Métodos analíticos para controle de produtos de origem animal e seus ingredientes: Métodos Físicos e Químicos. Diário Oficial da União, Brasília-DF.

ESCOBAR, A.L.S., XAVIER, F.B. (2013). Propriedades fitoterápicas do mel de abelhas. Revista UNINGÁ [periódico na internet];(37):159-172.

FARIAS, P.K.S., NOGUEIRA, G.A.B., SANTOS, S.G.A., PRATES, R.P., SILVA, J.C.R.L., SOUZA, C.N. (2016). Contagem de bactérias lácticas em iogurtes comerciais. Caderno de Ciências Agrárias [periódico na internet];8(3):38-44. 
Feitosa V.B.D., Oliveira E.N.A., Souza R.L.A., Feitosa B.F., Feitosa R.M. (2020). Estabilidade físicoquímica de iogurtes adoçados com mel de abelha Apis mellifera L. Ci. Anim. Bras. [periódico na internet];21:1-9.

GUERRA, M.J., MUJICA, M.V. (2010). Propriedades físicas e químicas de rapaduras granuladas. Ciênc Tecnol Aliment [periódico na internet]; 30(1):250-257.

IAL. Instituto Adolfo Lutz. (2008). Métodos físico-químicos para análise de alimentos. 1a ed. Digital. São Paulo: Instituto Adolfo Lutz, 1018p.

JACOPINI, L.A., MARTINS, E.N., LOURENÇO, D.A.L., DERÓIDE, C.A.S. (2011). Leite de cabra: características e qualidades. Rev ACTA Tecnológica [períódico na internet]; 6(1):168- 180.

JAFFE, W. (2015). Nutritional and functional components of non centrifugal cane sugar: A compilation of the data from the analytical literature. J. Food Compos. Anal [periódico na internet]; 43(1):194-202.

LACERDA, J.J.J., SANTOS, J.S., SANTOS, S.A., RODRIGUES, G.R., SANTOS, M.L.P. (2010). influence of physicochemical and elemental composition on honey colors produced by Apis mellifera in southwest bahia using multivariate analysis. Química Nova [periódico na internet];33(5):10221026.

MAZLOOMI, S.M., SHEKARFOROUSH, S.S., EBRAHIMNEJAD, H., SAJEDIANFARD, J. (2011). Effect of adding inulin on microbial and physicochemical properties of low fat probiotic yogurt. Iran J Vet Res, Shiraz University [periódico na internet];12(2):93-98.

MORAES, F.J., GARCIA, R.C., VASCONCELOS, E., CAMARGO, S.C., PIRES, B.G., HARTLEBEN, A.M., LIESENFELD, F., PEREIRA, D.J., MITTANCK, E.S., GIASSON, J., GREMASCHI, JR. (2014). Caracterização físico-química de amostras de mel de abelha africanizada dos municípios de Santa Helena e Terra Roxa (PR). Arq Bras Med Vet Zootec [periódico na internet];66(4):12691275.

OLIVEIRA, E.M.A, SANTOS, D.C. (2011). Análise físico-química de méis de abelhas africanizada e nativa. Rev Inst Adolfo Lutz [periódico na internet];70,(2):132-138.

PÉRICO E., TIUMAN T.S., LAWICH M.C., KRUGER R.L. (2011). Avaliação microbiológica e físicoquímica de méis comercializados no município de Toledo, PR. Rev Cienc Exatas Nat [periódico na internet];13(3): 365-382.

PIMENTEL T.C., GARCIA, S., PRUDENCIO, S.H. (2012a). Aspectos funcionais, de saúde e tecnológicos de frutanos tipo inulina. Bol Centro Pesqui Process Aliment [periódico na internet];30(1):103118.

PIMENTEL, T.C., GARCIA, S., PRUDENCIO, S.H. (2012b). Probiotic yoghurt with inulin-type fructans of different degrees of polymerization: physicochemical and microbiological characteristics and storage stability. Semina: Ciênc Agrár [periódico na internet];33(3):1059-1070. 
QUINTINO, S.S. (2012). Avaliação comparativa de iogurte produzido a partir da polpa natural de maracujá (Passiflora edulis Sims f. flavicarpa Deg.) e suco artificial. Encicl Biosf [periódico na internet];8(14):1830-1842.

SANTOS, B.M., OLIVEIRA, M.E.G., SOUSA, Y.R.F., MADUREIRA, A.R.M.F.M., PINTADO, M.M.E., GOMES, A.M.P., SOUZA, E.L., QUEIROGA, R.C.R.E. (2011). Caracterização físico-química e sensorial de queijo de coalho produzido com mistura de leite de cabra e de leite de vaca. Rev Inst Adolfo Lutz [periódico na internet];70(3):302-310.

SANTOS D.C., MOREIRA A.S., OLIVEIRA E.N.A., SANTOS Y.M.G. (2014). Elaboração de bebida tipo néctar de graviola adoçada com mel de Apis mellífera. Revista Caatinga [periódico na internet]; 27(4):216-225.

SBF. (2009). Sociedade Brasileira de Farmacognosia. Análise de mel. Disponível em: <http://www.sbfgnosia.org.br/Ensino/analise_mel.html>. Acesso 2018 Nov 02.

SILVA, A.G.F., BESSA, M.M., Silva JR. (2017). Elaboração e caracterização físico-química e sensorial de iogurte light prebiótico adoçado com mel. Rev Inst Laticínios Cândido Tostes [periódico na internet];72(2):74-84.

FAZ, S., CAV A. (2016). The assistat software version 7.7 and its use in the analysis of experimental data. Afr J Agr Res [periódico na internet];11(39):3733-3740.

YUCEL, Y.E., SULTANOGLU, P. (2013). Characterization of Hatay honeys according to their multielement analysis using ICP-OES combined with chemometrics. Food Chemistry [periódico na internet];140(1-2), 231237.

\section{COMO CITAR ESTE ARTIGO:}

LIMA, M. B. DE C., OLIVEIRA, E. N. A. DE, FEITOSA, B. F., FEITOSA, R. M., FREITAS, P. V. C. de. (2020). Estabilidade Físico-Química de iogurtes caprinos adoçados com méis de diferentes floradas. Holos. 36(5), 112.

\section{SOBRE OS AUTORES}

\section{MARINA BEATRIZ DE CARVALHO LIMA}

Técnica em Alimentos pelo IFRN, campus Pau dos Ferros-RN. E-mail: marinabeatriz1997@ hotmail.com ORCID ID: http://orcid.org/0000-0002-6153-6533

\section{EMANUEL NETO ALVES DE OLIVEIRA}

Graduado em Tecnologia de Alimentos pela Faculdade de Tecnologia CENTEC - Cariri (2009). Especialista em Ensino de Química pela Universidade Regional do Cariri (2009) e em Ciência dos Alimentos pela Universidade Federal de Pelotas (2012). Mestre (2012) e Doutor (2016) em Engenharia Agrícola na Área de Concentração em Processamento e Armazenamento de Produtos Agrícolas pela Universidade Federal de Campina Grande. Possui Pós-Doutorado em Engenharia Química pela Universidade de Coimbra, Portugal (2018) na área de Tecnologia e Controle de Qualidade de Vinhos. É Professor do Instituto Federal de Educação, Ciência e Tecnologia do Rio Grande do Norte (IFRN), lotado no Campus Pau dos Ferros/RN. Possui experiência na área de Engenharia Agrícola e Ciência e Tecnologia de Alimentos, atuando principalmente nos seguintes temas: Secagem e Armazenamento de Produtos Agrícolas, Processamento de Alimentos de Origem Vegetal e 
Animal, Análises Físicas e Químicas de Alimentos e Controle de Qualidade. E-mail: emanuel.oliveira16@gmail.com

ORCID ID: http://orcid.org/0000-0002-7000-8126

\section{BRUNO FONSÊCA FEITOSA}

Técnico em Alimentos pelo IFRN, campus Pau dos Ferros-RN (2016). Graduando no curso de Engenharia de Alimentos pela UATA/CCTA/UFCG, campus Pombal-PB (2017.1). Foi Tutor de Aprendizagem e Laboratório (TAL) na disciplina de Análise de Alimentos (2015/16) e bolsista pelo Parque Tecnológico da Paraíba (PaqTcPB) e Conselho Nacional de Desenvolvimento Científico e Tecnológico (CNPq). Atuou como membro da CONSUALI Empresa Júnior de Alimentos. Pesquisa na área de Ciência e Tecnologia de Alimentos, portando experiência em análises e controle de qualidade de alimentos, tecnologia e processamento de frutas, desenvolvimento de novos produtos e aproveitamento de resíduos agroindustriais. E-mail: brunofonsecafeitosa@live.com

ORCID ID: http://orcid.org/0000-0002-4183-3960

\section{REGILANE MARQUES FEITOSA}

Possui graduação em Tecnologia de Alimentos pelo Instituto Centro de Ensino Tecnológico. Mestrado e doutorado em Engenharia Agrícola pela Universidade Federal de Campina Grande e Pós- Doutorado em Engenharia de Processos pela Universidade federal de Campina Grande. Foi estagiária na Embrapa Algodão no campo experimental de Barbalha nas atividades de pesquisa e desenvolvimento. Trabalhou na vigilância sanitária do Juazeiro do Norte-CE. Atualmente é técnica no Instituto Federal de Alagoas, atuando nos laboratórios de físico-química, processamento de alimentos e microbiologia. E-mail: regilanemarques@gmail.com

ORCID ID: http://orcid.org/0000-0003-2627-0933

\section{PEDRO VICTOR CRESCÊNCIO DE FREITAS}

Técnico em Alimentos pelo Instituto Federal de Educação, Ciência e Tecnologia do Rio Grande do Norte (IFRN) e discente do curso de Engenharia de Alimentos da Universidade Federal de Campina Grande (UFCG), Centro de Ciência e Tecnologia Agroalimentar campus - Pombal ? PB. Faz parte do grupo de pesquisa do Centro Vocacional Tecnológico-CVT. Atual Diretor Presidente da Empresa Júnior CONSUALI, do Curso de Engenharia de Alimentos da UFCG campus de Pombal. Coordenador de Gestão Estratégica do CREA JÚNIOR Paraíba. Monitor de da disciplina Higiene na Industria de Alimentos. Tem experiência na área de Ciência e Tecnologia de Alimentos, atuando principalmente nos seguintes temas: Processamento de Frutas Tropicais, Analises de Alimentos, Condições Higiênico Sanitárias, Aproveitamento de Resíduos Agroindustriais, Elaboração de Produtos e Bebidas Alcoólicas e não alcoólicas, tecnologia de grãos e cereais, elaboração e adequação de rótulos em alimentos. E-mail: pedro.crescencio@hotmail.com

ORCID ID: http://orcid.org/0000-0002-7676-4328

Editor(a) Responsável: Francinaide de Lima Silva Nascimento

Pareceristas Ad Hoc: Odisséia Gaspareto e Fabiana Martins 


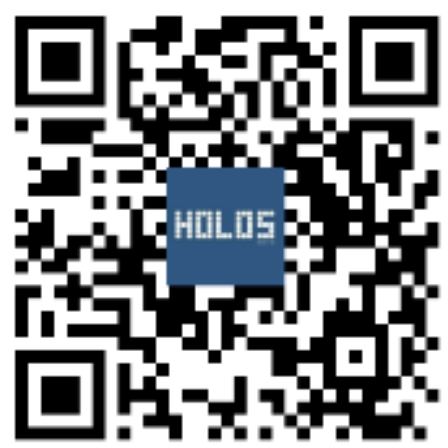

